\title{
STRUKTUR BERPIKIR SISWA PADA ZONE OF PROXIMAL DEVELOPMENT DALAM PEMBELAJARAN DISCOVERY LEARNING
}

\author{
Lutfiyah $^{1}$, Eric Dwi Putra ${ }^{2}$ \\ ${ }^{1,2}$ Program Studi Pendidikan Matematika, Universitas PGRI Argopuro Jember \\ Email: ${ }^{1}$ azkalutfimh@gmail.com, ${ }^{2}$ dwieric454@ gmail.com
}

\begin{abstract}
ABSTRAK
Kecemasan yang terjadi pada siswa saat pembelajaran matematika karena adanya hambatan dalam belajar matematika, salah satu cara yang dapat dilakukan guru yaitu dengan memberikan scaffolding oleh guru kepada siswa dengan arahan-arahan atau katakunci yang terbatas, agar dapat menyelesaikan hambatan yang dialami siswa sehingga struktur berpikir siswa dapat mencapai zone of proximal development. Tujuannya untuk mengetahui struktur berpikir siswa saat menggunakan pendekatan pembelajaran discovery learning agar siswa dapat menuju pada zone of proximal development dengan menggunakan scaffolding. Jenis penelitian ini deskriptif, hasil penelitian ini bahwa struktur berpikir S1 tidak sesuai dengan struktur masalah pada bagian Dt, Y3, Ha, dan K, sedangkan struktur berpikir S2, dan S3 tidak sesuai dengan struktur masalah pada bagian Dk, Dt, Y3, Ha, dan K. Untuk mencapai zone of proximal development masingmasing dari S1, S2 dan S3 sangat berbeda terlihat dari struktur berpikir yang telah dicapai, sehingga dalam penelitian ini siswa diberikan scaffolding dari ahli dimana pada zona perkembangan potensial mementingkan adanya bantuan dari ahli (guru) sehingga struktur berpikir yang dimiliki S1, S2 dan S3 sesuai dengan struktur masalah yang diberikan untuk menuju zone of proximal development. Kesimpulannya bahwa struktur berpikir siswa sesuai dengan struktur masalah yang diberikan dengan pemberian scaffolding oleh ahli (guru) kepada siswa sehingga zone of proximal development tercapai.
\end{abstract}

Kata Kunci: Struktur Berpikir, Zone Of Proximal Development, Discovery Learning, Scaffolding

\begin{abstract}
anxiety that occurs in students when learning mathematics because of obstacles in learning mathematics, one way that teachers can do this is by providing scaffolding by the teacher to students with limited directions or keywords, in order to solve the obstacles experienced by students so that the structure of students' thinking can reach the zone of proximal development. The aim is to find out the structure of students' thinking when using the discovery learning that students can go to the zone of proximal development by using scaffolding. This type of research is descriptive, the resultsof this study are that the SI thinking structure is not in accordance with the problem structure in the Dt, Y3, Ha, and K sections, while the $S 2$ and $S 3$ thinking structures are not in accordance with the problem structure in the Dk, Dt, Y3, Ha, sections and $K$. To achieve the zone of proximal development, each of S1, $S 2$ and $S 3$ is very different, it can be seen from the structure of thinking that has been achieved, so that in In these study students were given scaffolding from experts wherein the potential development zone the assistance from experts (teachers) was important. so that the thinking structure of $S 1, S 2$, and S3 is in accordance with the problem structure given to get to the zone of proximal development. The conclusion is that the structure of students' thinking is in accordance with the structure of the problem given by providing scaffolding by experts (teachers) to students so that the zone of proximal development is achieved.
\end{abstract}

Keywords: Thinking Structure, Zone Of Proximal Development, Discovery Learning, Scaffolding 


\section{PENDAHULUAN}

Matematika merupakan pelajaran yang dapat menimbulkan kecemasan bagi siswa, sebagai guru kita harus memikirkan kecemasan yang dialami siswa dalam menghadapi pembelajaran matematika, salah satu cara yang dapat dilakukan dengan memberikan bantuan kepada siswa saat mengalami hambatan dalam belajar, adanya bantuan dari guru maka siswa akan mampu belajar lebih baik. Kusumadewi mengatakan bahwa sebagian siswa menemui hambatan pada perkembangan kognitifnya, sehingga siswa tersebut harus mendapatkan bantuan untuk menghadapi hambantan yang sedang dialaminya saat belajar, dengan pemberian scaffolding maka struktur kognitif siswa akan menjadi lebih berkembang serta kompleks, scaffolding ini merupakan bantuan belajar dari guru kepada siswa yang sedang mengalami hambatan dalam belajarnya, sehingga pembelajaran akan lebih efektif jika guru dapat membantu siswa untuk mengembangkan struktur kognitifnya yang dapat membekali siswa dalam pembelajaran secara individu (Kusmaryono, Ubaidah, et al., 2020). Scaffolding yang diberikan oleh guru kepada siswa melalui katakunci atau arahan-arahan yang terbatas (Kusmaryono, Gufron, et al., 2020).

Manusia tidak hanya bergantung pada bawaan dirinya sendiri dan pengalaman pribadinya, tetapi reaksi bawaan dan historis serta pengalaman sosial dan juga pengalaman ganda,(Payong, 2020). Oleh sebab itu kita mengacu pada perbedaan antara apa yang dapat dilakukan oleh seseorang secara individu dan apa yang dapat dilakukan oleh seseorang dengan cara memperoleh bantuan dari orang lain yang lebih mampu Chaiklin (Danish et al., 2017). Berdasarkan hal tersebut, dimana kemampuan seseorang dalam melakukan sesuatu secara individu dan dengan bantuan orang lain, terbesit dalam pemikiran Vygotsky bahwa zone of proximal development (ZPD) merupakan zona yang mengharuskan seseorang untuk berpikir lebih jauh, dimana anak-anak untuk melakukan sesuatu tidak hanya dilakukan dalam 24 jam secara mandiri, tetapi memerlukan waktu lebih panjang untuk proses komunikasi yang berfungsi mengembangkan kompetensi siswa mencapai konseptual yang dimediasi secara budaya dan bernilai sosial (Smagorinsky, 2018). Zone of proximal development merupakan zona yang berada diantara zona perkembangan aktual dan zona perkembangan potensial, dimana dalam penelitian ini untuk mencapai zone of proximal development dilakukan scaffolding dari guru kepada siswa.

Vygotsky menciptakan zone of proximal development karena belajar dapat membangkitkan internal dimana proses perkembangan akan mampu beroperasi hanya ketika murid berinteraksi dengan orang-orang dilingkungannya (Abtahi, 2018). Menurut Vygotsky setiap siswa dapat memiliki zone of proximal development, dimana zone of proximal development merupakan jarak antara tingkat perkembangan aktual dan tingkat perkembangan potensial yang lebih tinggi (Eun, 2019; Kusmaryono, Ubaidah and Basir, 2020). Pencapaian zone of proximal development dalam pembelajaran matematika dan terciptanya pembelajaran yang lebih menyenangkan di dalam kelas, maka diperlukan suatu model pembelajaran. Model pembelajaran yang digunakan di dalam kelas merupakan upaya untuk mencapai tujuan pembelajaran yang dilakukan, semakin baik penerapan model pembelajaran di dalam kelas maka semakin tercapai tujuan pembelajaran tersebut (Dani \& Zubaidah, 2020).

Melakukan pembelajaran di dalam kelas, pemerintah memberikan saran untuk menerapkan beberapa pendekatan yang dapat dilakukan, dimana pada bagian karakteristik terdapat pembelajaran discovery learning yang merupakan salah satu pendekatan yang dipilih untuk pelaksanaan pembelajaran di dalam kelas, selain itu dalam peraturan pemerintah untuk memperkuat konsep serta keterampilan disarankan belajar berbasis discovery learning (Permendikbud Nomor 22 Tahun 2016 Tentang Standar Proses Pendidikan Dasar Dan Menengah, 2016). Berdasarkan hasil penelitian Nadya Zalvianin dan juga Yetty Zainil bahwa discovery learning memiliki dampak yang baik dari hasil proses belajar mengajar, dampaknya 
tidak hanya baik bagi siswa SMA tetapi juga baik bagi siswa SMP (Zalvianin \& Zainil, 2021) Dari beberapa hal diatas dapat terumuskan masalah bagaimanakah struktur berpikir siswa dalam zone of proximal development dengan menggunakan scaffolding pada saat pembelajaran discovery learning. Tujuan dari perumusan masalah diatas untuk mengetahui struktur berpikir siswa saat menggunakan pendekatan pembelajaran discovery learning agar siswa dapat menuju pada zone of proximal development dengan menggunakan scaffolding.

\section{METODE}

Jenis penelitian ini merupakan penelitian deskriptif, analisa deskriptif dilakukan pada hasil tes siswa untuk melihat struktur berpikirnya dalam zone of proximal development (ZPD), dimana zone of proximal development tersebut berada diantara jarak pada zona perkembangan aktual dan zona perkembangan potensial. Struktur masalah dalam penelitian ini dari soal program linear yang digambarkan dalam bentuk struktur dibawah ini.

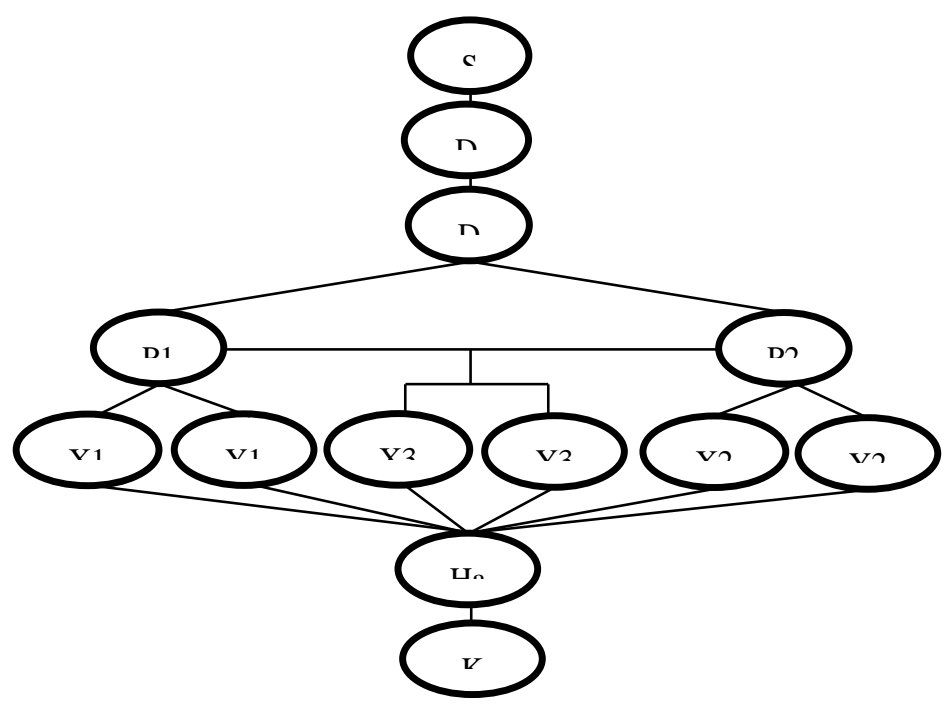

Keterangan :

S : soal

Dk : Diketahui

Dt : Ditanya

$\mathrm{P} 1$ : persamaan 1

$\mathrm{P} 2$ : persamaan 2

$\mathrm{X} 1$ : hasil variabel $\mathrm{x}$ pada persamaan 1

$\mathrm{Y} 1$ : hasil variabel y pada persamaan 1

$\mathrm{X} 2$ : hasil variabel $\mathrm{x}$ pada persamaan 2

Y2 : hasil variabel y pada persamaan 2

$\mathrm{X} 3$ : hasil variabel $\mathrm{x}$ pada persamaan $1 \& 2$

Y3 : hasil variabel y pada persamaan $1 \& 2$

Ha : Hasil Akhir

$\mathrm{K}$ : Kesimpulan

Gambar 1. Struktur Masalah

Tempat penelitian SMK Islam Bustanul Ulum Pakusari, subjek penelitian siswa kelas $\mathrm{X}$ SMK Islam Bustanul Ulum yang diambil secara acak sebanyak 3 siswa, siswa pertama disebut S1 dan siswa kedua disebut S2 sedangkan siswa ketiga disebut S3. tahap penelitian ada 3 yaitu tahap pendahuluan, tahap perencanaan, tahap tindakan, pada tahap pendahuluan yang dilalukan adalah wawancara dengan guru bidang studi tentang pembelajaran yang pernah dilakukan selama ini, selain itu pada tahap ini juga menentukan tiga subjek penelitian secara acak, pada tahap selanjutnya perencanaan yang dilakukan dengan menyusun soal tes yang akan diberikan pada siswa, tahap terakhir yaitu pelaksanaan tindakan dengan memberikan pembelajaran program linear dengan discovery learning. Teknik pengumpulan data yang dilakukan dengan wawancara dan tes, teknik analisa data deskriptif dengan cara mengelompokkan data-data penelitian agar dapat menentukan masing-masing kategori berdasarkan data deskriptif yang telah diperoleh. Seperti terlihat pada gambar dibawah. 


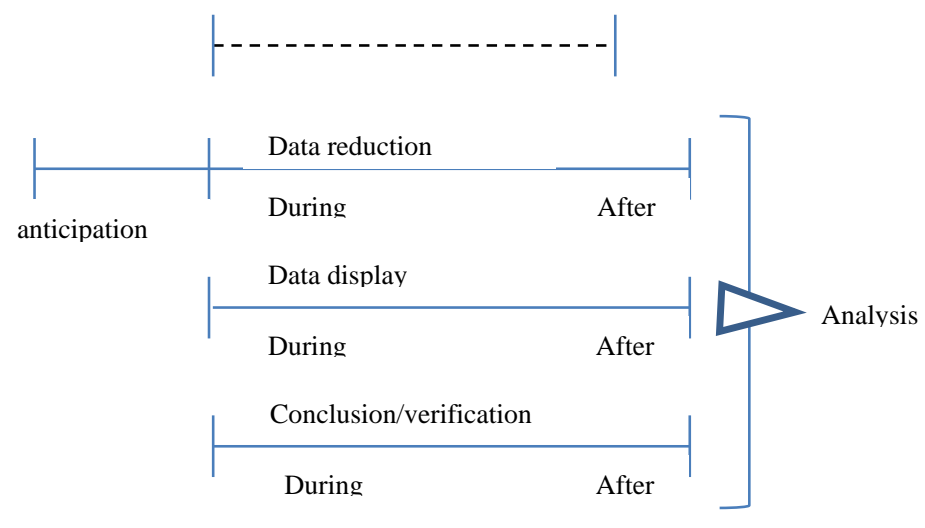

Gambar 2. Analisa data flow model (Sugiyono, 2014)

\section{HASIL}

Hasil penelitin ini berupa struktur berpikir S1, S2, dan S3 yang akan dideskripsikan secara detail, dimana simbol-simbol yang terdapat dalam struktur masalah sebagai berikut

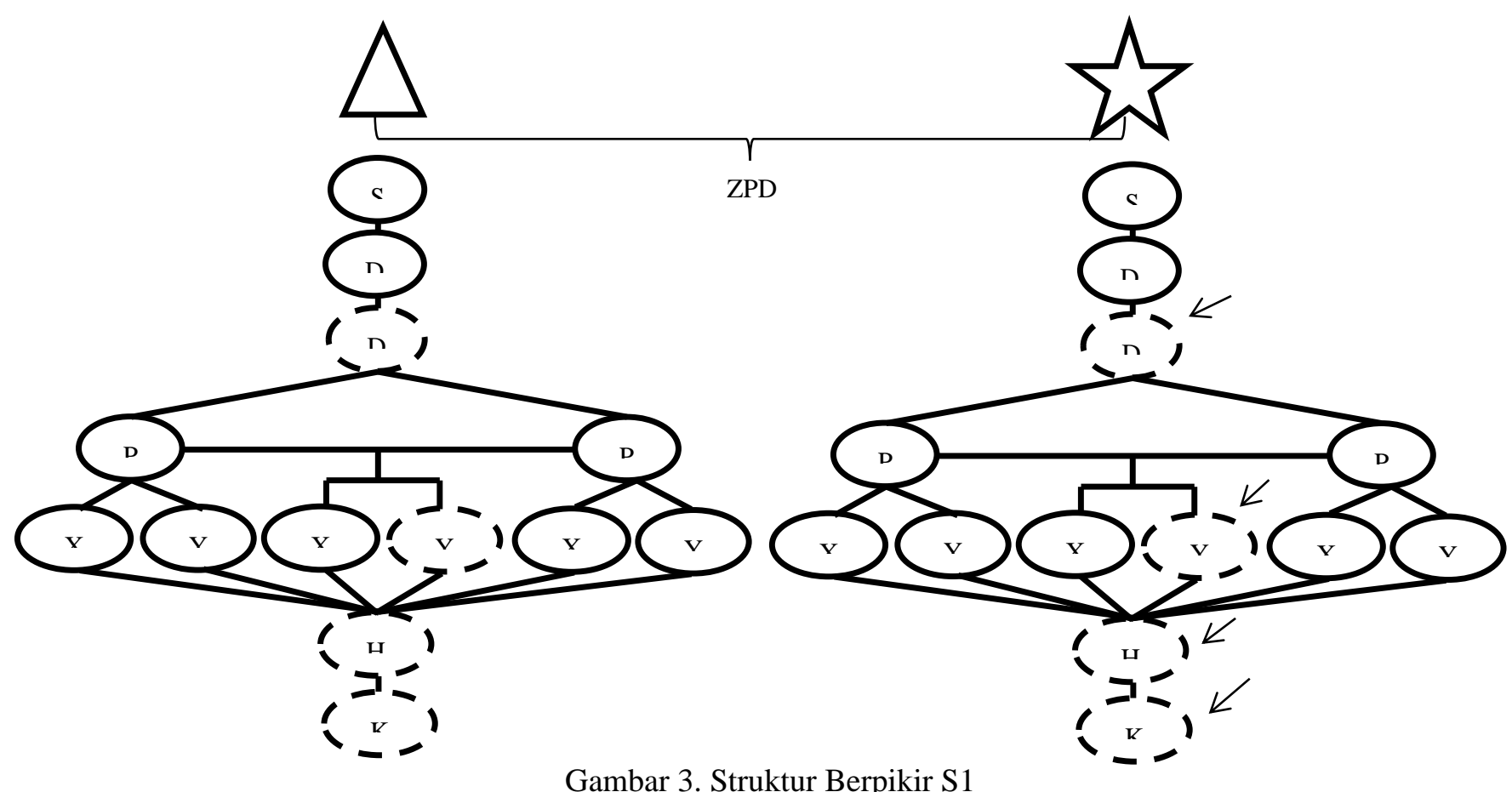

Tabel 1. Keterangan Simbol Kegiatan

$\begin{array}{ll}\text { Simbol } & \text { Keterangan } \\ \text { Struktur berpikir sesuai dengan struktur masalah } \\ \text { Tidak ada struktur berpikir }\end{array}$

Dari struktur berpikir S1 terlihat bahwa struktur berpikir pada zona perkembangan aktual belum sesuai dengan struktur masalah yang ada, beberapa bagian yang belum sesuai yaitu Dt, Y3, Ha dan K, Sedangkan pada zona perkembangan potensial setelah mendapatkan 
scaffolding dari guru, maka S1 mengatakan pada bagian Dt sebenarnya memahami apa yang ditanya tetapi lupa tidak menuliskan pada lembar jawaban, scaffolding yang diberikan saat Dt yaitu mengingatkan kembali urutan dalam menyelesaikan soal cerita, sedangkan pada penghitungan saat mencari Y3 ternyata S1 mengalami kesalahan dimana proses yang seharusnya dilakukan adalah mengurangi tetapi S1 malah melakukan pembagian, sehingga mengakibatkan terjadi kesalahan dalam mendapatkan hasil akhir dan berimbas pada penarikan kesimpulan, pada zona perkembangan potensial ini S1 mengalami perubahan struktur berpikirnya dengan adanya scaffolding dari orang yang lebih ahli (guru) yaitu mengingatkan kembali empat operasi aritmatika pada pertidaksamaan dengan memberi arahan bahwa apa yang membedakan antara penjumlahan, pengurangan, perkalian serta pembagian, sedangkan pada saat menentukan hasil akhir scaffolding yang diberikan hanya berupa arahan kepada S1 yaitu ketika salah satu variabel yang dikerjakan ada yang mengalami kesalahan, apa yang akan terjadi pada hasil akhir, setelah mendengarkan arahan tersebut S1 langsung menyadari bahwa hasil akhir yang ditulis ada kesalahan, saat membuat kesimpulan S1 menyadari bahwa pada saat terjadi kesalahan dalam menentukan Y3 dan Ha maka kesimpulan juga perlu diperbaiki, scaffolding yang diberikan yaitu mengingatkan S1 untuk meninjau kembali hasil dari tiap variabel yang sudah diselesaikan agar kesimpulan yang akan ditulis oleh S1 lebih tepat, sehingga struktur berpikir S1 dengan adanya scaffolding sesuai dengan struktur masalah yang diberikan dalam mencapai zone of proximal development.

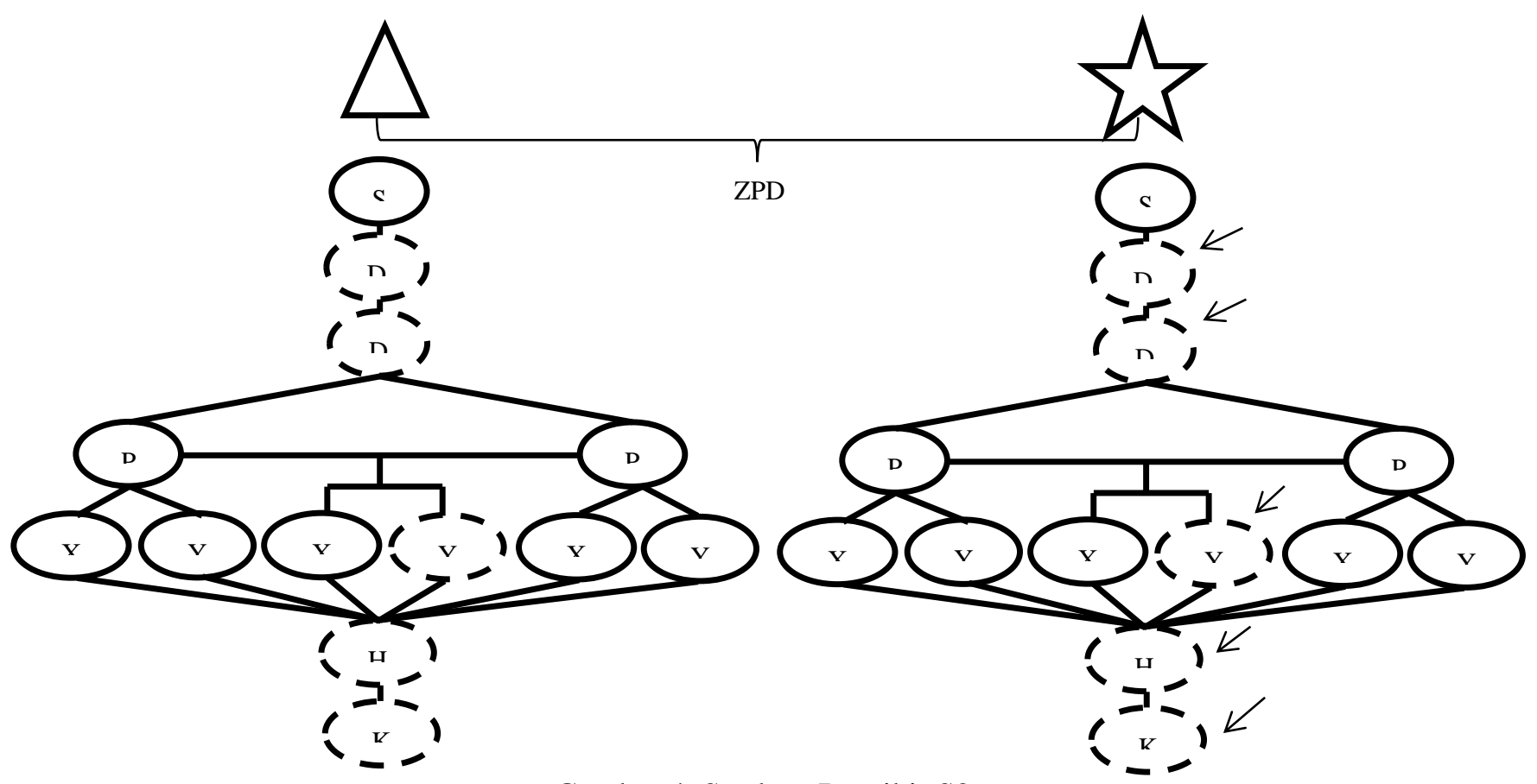

Gambar 4. Struktur Berpikir S2

Struktur berpikir S2 hampir sama dengan struktur berpikir S1, dimana ketidaksesuaian struktur berpikir S2 sama dengan struktur berpikir S1 hanya saja perbedaannya pada Dk, untuk struktur berpikir S1 pada bagian Dk sudah sesuai dengan struktur masalah sedangkan S2 tidak sesuai, untuk Dt, Y3, Ha dan K antara S1 dan S2 sama-sama struktur berpikirnya belum sesuai dengan struktur masalah, tetapi ketidaksesuaian dari masing-masing bagian tidak sama, pada bagian Dk dan Dt dari S2 mengatakan bahwa mereka tidak menulis dilembar jawaban karena takut terlalu lama sehingga menghabiskan waktu dalam menyelesaikan soal tersebut, scaffollding yang diberikan yaitu mengingatkan kembali urutan dalam menyelesaikan soal cerita serta memberi arahan bahwa apa yang diketahui dan ditanya dalam soal apabila ditulis dengan baik maka akan membantu memudahkan penyelesaian pada langkah berikutnya, 
sedangkan pada bagian mencari hasil dari Y3 tidak ada penyelesaian sampai akhir yang dilakukan oleh S2 atau dengan kata lain S2 tidak berusaha menyelesaikan penghitungannya, walaupun hasil dari Y3 tidak diketahui, S2 tetap melanjutkan pada pencarian Ha dimana pada penyelesaian Ha ini yang menjadi tanda tanya guru yaitu dari mana S2 mendapatkan penghitungan yang berkaitan dengan hasil Y3, tetapi S2 berusaha menyelesaikan Ha walaupun terjadi kesalahan dan menyebabkan kesalahan juga pada kesimpulan. Pada zona perkembangan potensial S2 juga mengalami perubahan struktur berpikirnya dengan scaffolding dari orang yang lebih ahli (guru) yaitu dengan memberikan pertanyaan terlebih dahulu pada S2 kenapa saat mencari Y3 penghitungannya tidak diselesaikan, ternyata S2 mengatakan lupa apakah dilakukan pembagian atau pengurangan oleh karena itu S2 tidak melanjutkan penyelesaian pada Y3 scaffolding yang diberikan dengan mengingatkan S2 pada empat operasi aritmatika dalam pertidaksamaan terutama pada pembagian dan pengurangan dengan mengingatkan kembali pada ulasan sebelumnya agar S2 dapat membedakan penyelesaian yang seharusnya dibagi atau dikurangi, sedangkan pada saat mencari Ha kembali memberi pertanyaan terlebih dahulu pada S2 ternyata informasi yang diperoleh S2 menggunakan nilai perkiraan agar bisa menyelesaikan Ha scaffolding yang diberikan dengan memberi arahan bahwa usaha dalam menyelesaikan Ha yang dilakukan oleh S2 sudah bagus, tetapi bagaimanapun usaha yang dilakukan untuk menyelesaikan Ha ketika Y3 tidak diselesaikan terlebih dahulu maka akan terjadi kesalahan terhadap Ha dimana Ha diperoleh dari X1, Y1, X2,Y2,X3 dan juga Y3 jika salah satu tidak diselesaikan maka Ha tidak akan maksimal nilai kebenarannya, setelah itu mengingatkan S2 untuk membaca kesimpulan yang telah dibuat dan diminta untuk mencermati dari masing-masing variabel agar kesimpulannya benar, sehingga struktur berpikir S2 dengan adanya scaffolding sesuai dengan struktur masalah yang diberikan dalam mencapai zone of proximal development.

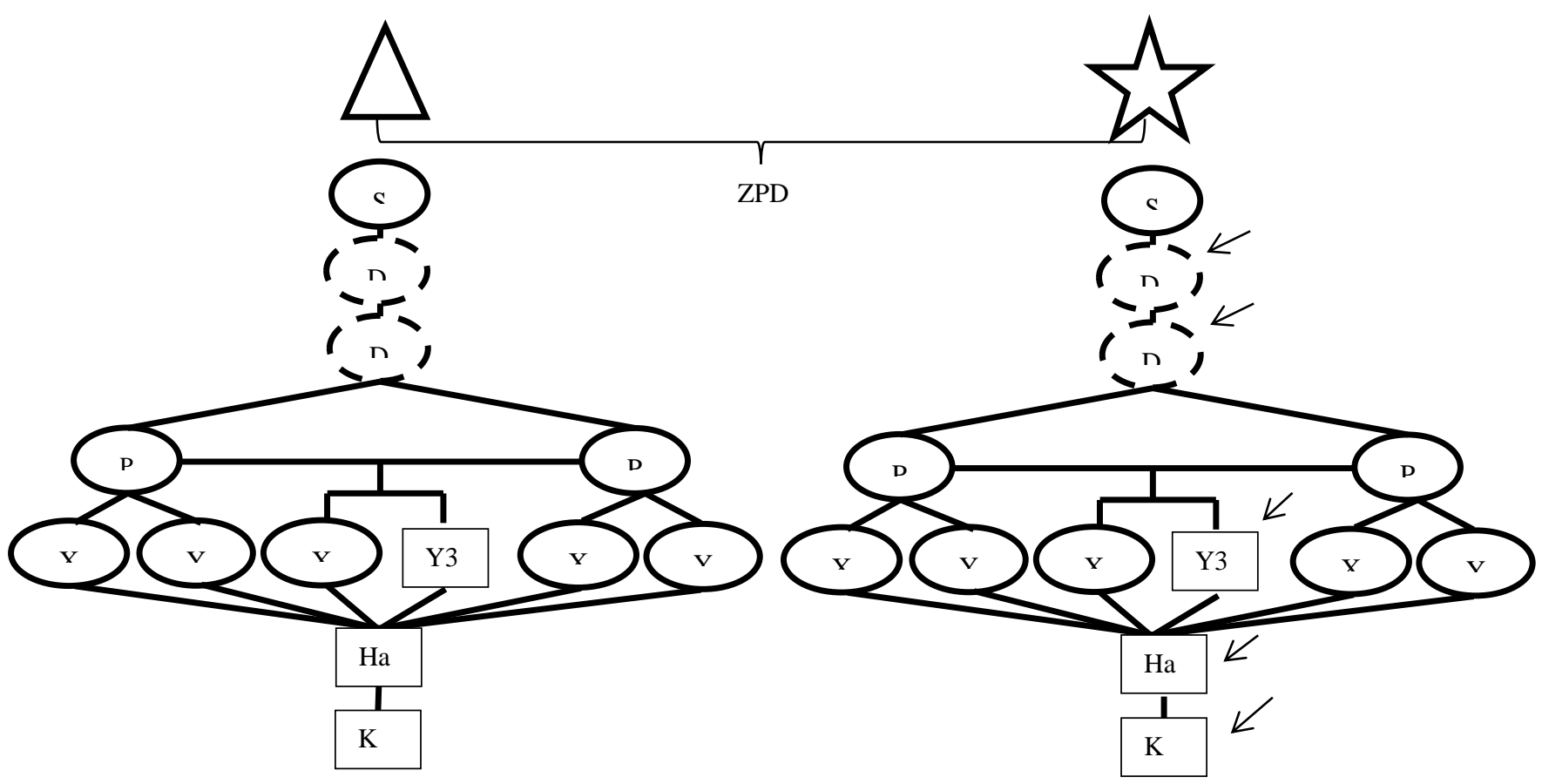

Gambar 5. Struktur Berpikir S3

Struktur berpikir S3 berbeda dengan struktur berpikir S1 dan S2 dimana S3 struktur berpikirnya tidak sesuai dengan struktur masalah pada bagian Dk, Dt, Y3, Ha, dan K, sepintas terlihat sama dengan S1 dan S2, tetapi jika dilihat secara detail bahwa pada Y3, Ha dan K tidak diselesaikan oleh S3, Dk dan Dt tidak ditulis dalam lembar jawaban sebab S3 kurang paham dalam penyelesaian soal tersebut, dan belum hafal terhadap langkah-langkah dalam 
pengerjaannya, sedangkan pada bagian Y3,Ha dan K tidak diselesaikan karena kehabisan waktu pengerjannya, sebab S3 mengatakan untuk menyeselesaikan persamaan linear butuh teliti takut terjadi kesalahan. Pada zona perkembangan potensial S3 juga mengalami perubahan struktur berpikirnya walaupun belum sempurna seperti struktur masalah pada bagian Dk dan Dt masih belum bisa menuliskan dengan baik apa saja yang diketahui dan ditanya dari soal tersebut, scaffolding yang diberikan meminta S3 untuk membaca soal dengan pelan serta meminta S3 untuk menghafalkan langkah-langkah dalam menyelesaikan soal cerita selain itu memberikan ulasan tentang cara menentukan Dk dan Dt dan memberi arahan bahwa Dk dan Dt perlu ditulis dan dipahami, untuk Y3, Ha dan K yang sebelumnya tidak diselesaikan dengan adanya scaffolding dari orang yang lebih ahli (guru) yaitu meminta S3 untuk berusaha menyelesaikan Y3, Ha, K dengan cara menyelesaikan Y3 terlebih dahulu dengan mengingatkan cara mensubstitusikan setelah ditulis oleh S3 lalu memberikan ulasan tentang materi sebelumnya yaitu empat operasi aritmatika, lalu meminta S3 melihat hasil penyelesain yang sudah diperoleh dari tiap variabel dan meminta melanjutkan pada Ha dimana S3 perlu dipantau untuk memasukkan variabel dalam tabel dan perlu memberikan sedikit ulasan tiap memasukkan tiap variabel dalam tabel sampai pada menghitung nilainya agar Ha terselesaikan, setelah itu meminta S3 untuk meninjau kembali dari Dk sampai pada Ha lalu meminta S3 menuliskan kesimpulan dengan memberi bantuan tata bahasa yang lebih baik, pemberian scaffolding terhadap S3 lebih sering diberikan pada S1 dan S2, struktur berpikir S3 dengan adanya scaffolding sesuai dengan struktur masalah yang diberikan dalam mencapai zone of proximal development.

\section{PEMBAHASAN}

Dalam pembahasan ini struktur berpikir S1, S2 dan S3 akan disajikan dalam bentuk rekapitulasi Struktur berpikir pada zona perkembangan aktual dan zona perkembangan potensial sampai pada zone of proximal development, dengan tanda $(\sqrt{ })$ yang berarti struktur berpikirnya sudah sesuai dengan struktur masalah sedangkan tanda (-) berarti struktur berpikirnya belum sesuai dengan struktur masalah, dimana hal tersebut terlihat dalam tabel dibawah.

Tabel 2. Rekapitulasi Struktur Berpikir

\begin{tabular}{lllllllll}
\hline No. & Struktur & \multicolumn{8}{l}{ Zona Perkembangan Aktual } & \multicolumn{5}{l}{ Zona Perkembangan Potensial } & ZPD \\
\cline { 3 - 9 } & Masalah & S1 & S2 & S3 & S1 & S2 & S3 & \\
\hline 1 & Dk & $\sqrt{ }$ & - & - & $\sqrt{ }$ & $\sqrt{ }$ & $\sqrt{ }$ & $\sqrt{ }$ \\
2 & Dt & - & - & - & $\sqrt{ }$ & $\sqrt{ }$ & $\sqrt{ }$ & $\sqrt{ }$ \\
3 & P1 & $\sqrt{ }$ & $\sqrt{ }$ & $\sqrt{ }$ & $\sqrt{ }$ & $\sqrt{ }$ & $\sqrt{ }$ & $\sqrt{ }$ \\
4 & P2 & $\sqrt{ }$ & $\sqrt{ }$ & $\sqrt{ }$ & $\sqrt{ }$ & $\sqrt{ }$ & $\sqrt{ }$ & $\sqrt{ }$ \\
5 & X1 & $\sqrt{ }$ & $\sqrt{ }$ & $\sqrt{ }$ & $\sqrt{ }$ & $\sqrt{ }$ & $\sqrt{ }$ & $\sqrt{ }$ \\
6 & Y1 & $\sqrt{ }$ & $\sqrt{ }$ & $\sqrt{ }$ & $\sqrt{ }$ & $\sqrt{ }$ & $\sqrt{ }$ & $\sqrt{ }$ \\
7 & X2 & $\sqrt{ }$ & $\sqrt{ }$ & $\sqrt{ }$ & $\sqrt{ }$ & $\sqrt{ }$ & $\sqrt{ }$ & $\sqrt{ }$ \\
8 & Y2 & $\sqrt{ }$ & $\sqrt{ }$ & $\sqrt{ }$ & $\sqrt{ }$ & $\sqrt{ }$ & $\sqrt{ }$ & $\sqrt{ }$ \\
9 & X3 & $\sqrt{ }$ & $\sqrt{ }$ & $\sqrt{ }$ & $\sqrt{ }$ & $\sqrt{ }$ & $\sqrt{ }$ & $\sqrt{ }$ \\
10 & Y3 & - & - & - & $\sqrt{ }$ & $\sqrt{ }$ & $\sqrt{ }$ & $\sqrt{ }$ \\
11 & Ha & - & - & - & $\sqrt{ }$ & $\sqrt{ }$ & $\sqrt{ }$ & $\sqrt{ }$ \\
12 & K & - & - & - & $\sqrt{ }$ & $\sqrt{ }$ & $\sqrt{ }$ & \\
\hline
\end{tabular}

Dalam zona perkembangan aktual struktur berpikir S1 masih belum sesuai dengan struktur masalah begitu juga dengan struktur berpikir S2 dan S3, tetapi untuk mencapai zone of proximal development masing-masing dari S1, S2 dan S3 sangat berbeda terlihat dari struktur berpikir yang telah dicapai, sehingga masing-masing siswa untuk bergerak pada zona perkembangan aktual untuk mencapai zona perkembangan aktual berikutnya masing-masing berbeda, dari persepektif konstruktivisme sosial Vygotsky menganut pedagogi optimisme 
dimana melihat pendidikan dan pembelajaran sebagai faktor penting dalam perkembangan individu, dengan pandangan ini ada hubungan erat antara pembelajaran dan pengembangan kognitif dengan media interaksi sosial (Payong, 2020), sehingga dalam penelitian ini siswa diberikan scaffolding dari ahli (guru) dimana pada zona perkembangan potensial mementingkan adanya bantuan dari ahli (guru) sehingga struktur berpikir yang dimiliki S1, S2 dan S3 sesuai dengan struktur masalah yang diberikan untuk menuju zone of proximal development. Hal ini sesuai dengan pernyataan Vygotsky bahwa siswa dengan kemampuannya sendiri dapat melakukan tugas pada tingkat kognitif tertentu, sedangkan saat bekerjasama dengan orang yang lebih dewasa (guru) siswa akan mampu berada ditingkat lain yang lebih tinggi, dimana variasi antara dua tingkat tersebut adalah zone of proximal development (Bikmaz et al., 2010). Terlihat juga pada hasil penelitian yang dilakukan oleh (Susilowati et al., 2017) disimpulkan bahwa rendahnya kebiasaan berpikir kritis mahasiswa dapat diatasi dengan pemberian scaffolding yang terbukti lebih efektif dengan capaian peningkatan kebiasaan berpikir kritis mahasiswa sebesar 19,25\% dari rata-rata nilai yang diperoleh. Hal tersebut sesuai dengan hasil penelitian ini bahwa masing masing subjek dengan adanya scaffolding dari ahli (guru) struktur berpikirnya mencapai struktur masalah yang diberikan.

Dari tabel diatas terlihat antara S1, S2 dan S3 untuk menuju zone of proximal development ada keseragaman yaitu pemberian scaffolding, tetapi pada kenyataan dilapangan scaffolding yang diberikan oleh ahli (guru) kepada S1, S2, Maupun S3 sangat berbeda, pencapaian zone of proximal development oleh S1, S2 dan S3 tidak sama begitu juga dengan interkasi sosial yang terjadi saat pemberian scaffolding juga tidak ada yang sama. Dengan kata lain guru harus dapat menempatkan bantuan kepada siswa sehingga memungkinkan pengetahuan baru terbentuk, kesalahan konsep maupun konsep yang tidak lengkap dapat dikorensi, sedangkan konsep yang terlupakan dapat diingatkan kembali, bantuan tersebut dapat merangsang aktivitas pembelajaran dalam zone of proximal development menurut Holton \& Clarke (Bikmaz et al., 2010). Selain itu Spectrum (Sulistyorini, 2017) menyatakan bahwa scaffolding dalam pembelajaran merupakan bantuan terstruktur yang bisa digunakan dalam membantu siswa menyelesaikan tugas baru serta memahami konsep yang tidak bisa dicapai jika dilakukan sendiri oleh siswa.

\section{SIMPULAN DAN SARAN}

Kesimpulan yang diperoleh dari hasil analisa diatas bahwa struktur berpikir siswa sesuai dengan struktur masalah yang diberikan dalam zone of proximal development dengan pemberian scaffolding saat pembelajaran discovery learning. Dari hasil penelitian ini, saran yang peneliti sampaikan 1) perlu adanya penelitian lebih lanjut tentang struktur berpikir siswa dalam pembelajaran khususnya matematika untuk mencapai zone of proximal development pada masa pandemi, 2) selain itu, perlu juga diteliti bagaimana pemberian scaffolding yang efektif dalam pembelajaran matematika pada masa pandemi.

\section{DAFTAR RUJUKAN}

Abtahi, Y. (2018). Pupils, tools and the Zone of Proximal Development. Research in Mathematics Education, 20(1), 1-13. https://doi.org/10.1080/14794802.2017.1390691

Bikmaz, F. H., Celebi, O., Ata, A., Ozer, E., Soyak, O., \& Recber, H. (2010). Scaffolding Strategies Applied by Student Teachers to Teach Mathematics. Educational Research Association The International Journal of Research in Teacher Education The International Journal of Research in Teacher Education, 1(1), 25-36. https://www.researchgate.net/profile/HandeRecber/publication/268266108_Scaffolding_Strategies_Applied_by_Student_Teachers_to_Teac h_Mathematics/links/54bcd0500cf24e50e940942e/Scaffolding-Strategies-Applied-by-StudentTeachers-to-Teach-Mathematics.pdf

Dani, U., \& Zubaidah, T. (2020). Improving Year 7 Students' Mathematics Communication Skills by The Discovery Learning Model. Journal of Mathematics and Mathematics Education, 10(2), 39. https://doi.org/10.20961/jmme.v10i2.47084

Danish, J., Saleh, A., Andrade, A., \& Bryan, B. (2017). Observing complex systems thinking in the 
zone of proximal development. Instructional Science, 45(1), 5-24. https://doi.org/10.1007/s11251-016-9391-z

Eun, B. (2019). The zone of proximal development as an overarching concept: A framework for synthesizing Vygotsky's theories. Educational Philosophy and Theory, 51(1), 18-30. https://doi.org/10.1080/00131857.2017.1421941

Kusmaryono, I., Gufron, A. M., \& Rusdiantoro, A. (2020). Effectiveness of Scaffolding Strategies in Learning Against Decrease in Mathematics Anxiety Level. NUMERICAL: Jurnal Matematika Dan Pendidikan Matematika, 4, 13-22. https://doi.org/10.25217/numerical.v4i1.770

Kusmaryono, I., Ubaidah, N., \& Basir, M. A. (2020). the Role of Scaffolding in the Deconstructing of Thinking Structure: a Case Study of Pseudo-Thinking Process. Infinity Journal, 9(2), 247. https://doi.org/10.22460/infinity.v9i2.p247-262

Payong, M. R. (2020). Zona perkembangan proksimal dan pendidikan berbasis konstruktivisme sosial menurut Lev Semyonovich Vygotsky. Jurnal Pendidikan Dan Kebudayaan Missio, 12(2), 164 178. https://doi.org/10.36928/jpkm.v12i2.589

Smagorinsky, P. (2018). Deconflating the ZPD and instructional scaffolding: Retranslating and reconceiving the zone of proximal development as the zone of next development. Learning, Culture and Social Interaction, 16(September), 70-75. https://doi.org/10.1016/j.lcsi.2017.10.009

Sugiyono. (2014). Metode Penelitian Kuantitatif, Kualitatif, dan $R \& D$ (20th ed.). CV. Alfabeta. www.cvalfabeta.com

Sulistyorini, Y. (2017). Analisis Kesalahan Dan Scaffolding Dalam Penyelesaian Persamaan Diferensial. KALAMATIKA Jurnal Pendidikan Matematika, 2(1), 91-104. https://doi.org/10.22236/kalamatika.vol2no1.2017pp91-104

Susilowati, E., Rusdiana, D., \& Kaniawati, I. (2017). Efektivitas Perkuliahan Gelombang dan Optika berbasis scaffolding terhadap peningkatan kebiasaan berpikir kritis mahasiswa. WaPFi (Wahana Pendidikan Fisika), 2(2), 68. https://doi.org/10.17509/wapfi.v2i2.6976

Zalvianin, N., \& Zainil, Y. (2021). The Implementation of Discovery Learning for Reading Skill in EFL Classroom at SMPN 8 Padang. Journal of English Language Teaching, 10(1), 61-74. https://doi.org/10.24036/jelt.v10i1.1113786

Permendikbud nomor 22 tahun 2016 tentang standar proses pendidikan dasar dan menengah, 3 Resma 13 (2016). 